\title{
Empirical research on skill premium in China
}

\author{
Jian-yun Cao \\ School of Economics and Commerce, South China University of Technology, Guangzhou \\ Guangdong 510006, China \\ jycao@scut.edu.cn
}

Keywords: Skill premium; Skilled labor market; Industrial agglomeration.

\begin{abstract}
Based on the panel data in 1989-2014, the paper carries out an empirical research on skill premium focusing on the influence of industrial agglomeration and entry barriers. The results show that skill premium occurred in 1993 in China and since then it was expanded rapidly; the level of skill premium is highly correlated to the types and extent of the industrial agglomeration; barriers to entering the skilled labor market are positively correlated to skill premium.
\end{abstract}

\section{Introduction}

Since the reform and opening-up, the remuneration of skills and unskilled labor began to show a polarization trend along with the rapid economic growth, the skill premium rose from 0.73 in 1978 to 3.68 in $2010^{[1]}$. Existing studies mainly focus on international trade and technological progress. For example, Shao Min et al. found that Chinese FDI is mainly concentrated in the lower end of high-end sectors, FDI technology spillovers mainly bias toward unskilled labor, foreign investment can narrow Chinese skill premium. ${ }^{[2]}$ Song Donglin et al. confirmed the existence of skill-biased technological progress in China, and verified that the phenomenon of the skill premium in China mainly results from the bias effect of technological progress. ${ }^{[3]}$

However, the existing research is based on the complete free movement of labor factors between industries without considering the impact of Chinese labor market segmentation on skill premium. Labor wage is determined largely by supply and demand of labor market. Labor market segmentation can affect supply and demand of labor of different kinds, resulting in labor price distortions ${ }^{[4]}$. Thus, researches on skills premium can not ignore the impact of labor market segmentation on supply and demand of labor of different skill levels. Secondly, the existing researches mainly focus on the effect of technology advancement bias originated from international trade on skill premium, but not on the effect of technology advancement bias originated from industrial agglomeration on skill premium. In fact, technical level and technical bias are different for different industries and different stages of development of the same industry. Also, the level of industrial agglomeration determines the extent of the knowledge and technology spillover effect of industrial agglomeration. Yang Renfa thought that China's manufacturing agglomeration did not take advantage of the knowledge and technology spillover effect, but only increased the demand for unskilled labor. Agglomeration of producer services industry had a significant knowledge and technology spillover effect that increased the demand for skilled labor. ${ }^{[5-6]}$ Therefore, it is necessary to explore the mechanism that how do different industries and different types of industrial agglomeration affect the skill premium. Based on this, this paper combines the characteristics of China's labor market segmentation to construct a unified analytical framework to study the mechanism of industrial agglomeration and labor market segmentation on skill premium. Also, we measure the impact of industrial agglomeration and labor market segmentation on skill premium. In the end, we recommend the policies of industrial development and labor market construction to 
reduce skill premium.

\section{Theoretical Analysis and Hypothesis of Skill Premium}

Based on Dixit \& Stiglitz's monopolistic competition D-S model, this paper introduces the assumption of increasing returns to scale, constructs the wage determination equation, and analyzes the mechanism of industrial agglomeration and labor market segmentation on skill premium.

Hypothesis 1: Consumers use all of their income for the consumption of the two types of final products, the skill-intensive products "s" and the labor-intensive products "l”. The consumers have the same preferences and their utility conforms to the invariant substitution elasticity CES function:

$$
U=\left[u_{s} Q_{s}^{\rho}+u_{l} Q_{l}^{\rho}\right]^{1 / \rho}
$$

Where, $u$ represents share of the two kinds of products in consumption expenditure, $u_{s}+u_{l}=1, \sigma \equiv 1 /(1-\rho)$, and $\sigma$ represents the substitution elasticity between two kinds of products. when $\sigma>1$, the two kinds of products have substitutive relations. When $0<\sigma<1$, the two kinds of products have complementary relations. This paper assumes that $\sigma>1$.

Use $\mathrm{P}$ as the market price of the product, then the consumer's product demand of utility maximization is:

$$
Q_{m}^{D}=I u_{m}^{\sigma} \frac{P_{m}^{-\sigma}}{G^{1-\sigma}} \quad m=l, s
$$

where, $\quad G=\left[u_{l}^{\sigma} P_{l}^{1-\sigma}+u_{s}^{\sigma} P_{s}{ }^{1-\sigma}\right]^{1 /(1-\sigma)}$ 。

Hypothesis 2: There are economies of scale in production and only one factor is input into production. The factor is labor. The inputs of labor for production of the two kinds of final products are $L_{s}=F_{s}+C_{s} Q_{s}$ and $L_{l}=F_{l}+C_{l} Q_{l}$ respectively. $\mathrm{F}$ and $\mathrm{C}$ are fixed inputs and marginal inputs respectively, $\mathrm{Ls}$ and $\mathrm{Ll}$ are number of skilled labor and unskilled labor respectively.

The marginal input of labor depends on the level of technological progress and technical efficiency in production. According to the theory of New Economic Geography and Spatial Agglomeration, spatial agglomeration of industries, which will bring the labor market sharing effect and knowledge, technology spillover effect, influences technology advancement and labor allocation efficiency, thus affecting the marginal input. The relationship between industrial agglomeration and marginal input of labor at different skill levels can be expressed as follows:

$$
C_{m}=\beta a g g^{\alpha_{m}}
$$

Where, agg is the degree of industrial agglomeration, a measuring the degree of industrial agglomeration's impact on the marginal input of labor. Thus, the labor inputs required for the production of two types of products are further expressed as $L_{s}=F_{s}+\beta a g g^{\alpha_{s}} Q_{s}$ and $L_{l}=F_{l}+\operatorname{\beta agg}^{\alpha_{l}} Q_{l}$, respectively.

According to the principle of profit maximization, the relationship between labor wage and product price is as follows: 


$$
w_{m}=\frac{1}{\beta a g g^{\alpha_{m}}} P_{m}\left(1-\frac{1}{\sigma}\right)
$$

In long-term equilibrium, the manufacturer's profit is zero, so the profit-maximizing yield level is:

$$
Q_{m}^{\prime}=F_{m}(\sigma-1) / \beta a g g^{\alpha_{m}}
$$

Combining equation (2) and (5), we can find the labor demand that satisfies the consumer utility maximization and product market clearing condition:

$$
L_{m}=\frac{I u_{m}^{\sigma}(\sigma-1)^{\sigma-1} G^{\sigma-1}}{w_{m}^{\sigma} \sigma^{\sigma-1}\left(\beta a g g^{\alpha_{m}}\right)^{\sigma-1}}
$$

Hypothesis 3: Suppose that the labor market is divided into two types: competitive and non-competitive. In China, there are multiple segmentation of labor market. Household registration, ownership, industry and education system all lead to the segmentation of labor force. Moreover, there are crosses among these segmentation. For example, Degree of education and the probability of entering the monopoly industry is positively correlated. ${ }^{[7]}$ It is further assumed that the unskilled labor is concentrated in a competitive labor market and the skilled labor is concentrated in a noncompetitive market with barriers to entry. ${ }^{[8]}$ Industry monopoly, ownership discrimination and other multi-segmentation make the market a shortage of labor. Additionally, they hinder the transformation of unskilled labor to skilled labor, and are harmful to narrow the gap between supply and demand of skilled labor, resulting in a wage premium. Using bte to measure the barriers to entry caused by the labor market segmentation, the labor demand for the two kinds of labor markets is:

$$
L_{m}^{D}=\frac{1}{1-b t e_{m}} L_{m}
$$

There are no entry barriers to the unskilled labor market: $b t e_{l}=0$; but there are entry barriers to the skilled labor market: $0<b t e_{s}<1$.

Combining Eq. (6) and Eq. (7), we obtain the equilibrium of product market and labor market, the skill premium is:

$$
\frac{w_{s}^{\prime}}{w_{l}^{\prime}}=\left(1-b t e_{s}\right)^{-1 / \sigma} \times \operatorname{agg}^{-(\sigma-1)\left(\alpha_{s}-\alpha_{l}\right) / \sigma} \times\left(\frac{L_{s}}{L_{l}}\right)^{-1 / \sigma} \times \frac{u_{s}}{u_{l}}
$$

It is shown that the factors affecting the skill premium include entry barriers $\left(b t e_{s}\right)$, industrial agglomeration effects ( $a g g^{\alpha_{s}-\alpha_{l}}$ ), relative supply of labor $\left(L_{s} / L_{l}\right)$, substitution elasticity of the two types of products $(\sigma)$ and the relative share of products in consumer spending $\left(u_{s} / u_{l}\right)$. The impact of industrial agglomeration on skill premium depends on the level of industrial agglomeration and its relative influence on the marginal input of different skill levels. The greater the entry barriers caused by labor market segmentation, the higher the skill labor price and the higher the skill premium.

\section{Empirical analysis of skill premium}

\subsection{Models and data}

According to the above theoretical model, the following measurement models are constructed: 


$$
\operatorname{lnyj}_{i t}=\beta_{0}+\beta_{1} \operatorname{lnbte}_{i t}+\beta_{2} \operatorname{lnagg}_{i t}+\beta_{3} \operatorname{lnldb}_{i t}+\beta_{4} \operatorname{lnzcb}_{i t}+v_{i}+\varepsilon_{i t}
$$

Where yj is the skill premium, ldb is the relative supply of skilled labor and unskilled labor, zcb is the relative share of the two kinds of products in consumption expenditure, $\mathrm{i}$ is the province, $\mathrm{t}$ is the time, $v$ is the non-observed fixed effect of the provinces, $\varepsilon$ is a random disturbance term.

In order to explore the impacts of different industries and different types of industrial agglomeration on skill premium, the variables of manufacturing agglomeration $\left(\mathrm{agg}^{\mathrm{m}}\right)$, producer services agglomeration $\left(a g g^{s}\right)$, manufacturing and producer services agglomeration ( $\left.a g g^{c o}\right)$ are added into the model. At the same time, taking into account that factors such as openness (open), capital intensity $(c d)$, government investment ( $g o v$ ), etc. will inevitably affect the relative supply and demand of labor at different skill levels, thus affecting the skill premium. So these factors are also added into the model as control variables. The final measurement model is:

$$
\begin{aligned}
& \operatorname{lnyj}_{i t}=\beta_{0}+\beta_{1} \text { Inbte }_{i t}+\beta_{21} \operatorname{lnagg}_{i t}^{m}+\beta_{22} \operatorname{lnagg}_{i t}^{s}+\beta_{23} \operatorname{lnagg}_{i t}^{c o}+\beta_{3} \operatorname{lnldb}_{i t} \\
& +\beta_{4} \text { Inzcb }_{i t}+\beta_{5} \text { Inopen }_{i t}+\beta_{6} \text { Incd }_{i t}+\beta_{7} \operatorname{lngov}_{i t}+v_{i}+\varepsilon_{i t}
\end{aligned}
$$

The data of skill premium is calculated based on the population of the junior college or above and hourly wage of the high school and below in the Chinese Health and Nutrition Survey (CHNS) database. The survey has been carried out nine times since 1989, involving 12 provinces and autonomous regions in Beijing, Shanghai, Liaoning, Heilongjiang, Jiangsu, Shandong, Henan, Hubei, Hunan, Guangxi, Guizhou and Chongqing. Data shows in 1989 there is no significant difference between the two wages. But the gap gradually expanded after 1993. in 2011, the two wages were 34.44 times and 15.97 times of 1989 respectively. The data of other years are obtained by interpolation method and trend extrapolation method.

Intra-industry agglomeration and inter-industry agglomeration are measured by location entropy and the relative differences of intra - industry agglomeration index respectively.

The entry barriers of the labor market segmentation are measured by the relative difference between the development degree of the product market and the factor market. The larger the relative difference, the greater the market distortions caused by the labor market segmentation, and the greater the barriers to labor market entry.

The ratio of skilled and unskilled labor is measured by the ratio of laborers with college degree or higher to the other labor force; since the relative share of the two categories of products in the consumption expenditure is not available, this paper use the per capita GDP to measure it as the level of income determines the consumption structure to a large extent. The degree of openness, the capital intensity and the government's financial input are measured by the ratio of the total import and export volume to GDP, the per capita fixed capital stock and the ratio of fiscal expenditure to GDP, respectively.

\subsection{The Empirical Test and Results}

Considering that Chongqing was set up as a municipality in 1997 and was included in the scope of CHNS survey in 2011, the study will be conducted in 11 provinces and regions except Chongqing. The sample period is from 1989 to 2014. Since the number of cross-sections of panel data is less than the number of periods, this paper uses Stata's XTGLS regression. And we select the fixed effect model according to the Hauseman test results. However, there are heteroskedasticity, cross-section correlation and autocorrelation in the model, which makes the estimation coefficient and its standard error inaccurate, so we corrected the model with XTSCC in further.

In Table 1, the models (1) - (3) are the whole sample estimation results. In the model (1), there are no variables such as inter-industry agglomeration and labor market entry barriers. The 
goodness-of-fit R2 is 0.456 . In the model (2) , inter-industry agglomeration is added to the model and R2 is increased to 0.471 . In model (3), inter-industry agglomeration and labor market entry barriers are added to the model and R2 is increased to 0.493. The regression coefficients of industrial agglomeration and labor market entry barriers are all significant at the level of 5\%, indicating that entry barriers caused by industrial agglomeration and labor market segmentation have an important effect on skill premium. The F-test results of all models show that the model coefficients are statistically significant on the whole. And the regression coefficients of the variables in the model (1) - (3) are consistent in symbol, indicating that the effects of each variable on the skill premium are very robust. All samples were analyzed using the results of model (3). Models (4) - (5) are phased estimation results, corresponding to the periods of 1989-2002 and 2003-2014, respectively. The models (6) - (7) are the regional estimation results, corresponding to regions of 6 provinces in the east and 5 provinces in the centre and west respectively.

Industry agglomeration has a significant impact on the skill premium in China. However, different forms of industrial agglomeration have different effects on skill premium. Manufacturing agglomeration has a significant negative impact on the skill premium. For every $1 \%$ increase in manufacturing agglomeration, skill premium decreases by $0.608 \%$. Producer services agglomeration has a significant positive impact on the skill premium. For every $1 \%$ increase in producer services agglomeration, skill premium increases by $0.391 \%$. For the huge difference among industries of intra-industry agglomeration's effect on skill premium, this paper argues that this is related to the nature of the industry itself and the stage of its development. Industry of different nature or at different stages of development has differences in its technical level, technical bias and the external influence of the agglomeration development. This difference determines that the development of the agglomeration of different industries has different effects on the labor supply and demand of different skill levels and skill premium. As China's manufacturing industry is "locked" in the global value chain of low-end, manufacturing agglomeration mainly affects the supply and demand of unskilled labor because of low entry barriers to labor. Supply-side effects for the development of manufacturing agglomeration makes a large number of rural surplus labor transfer out. The demand-side effects is due to the expansion of industrial scale. when the demand for unskilled labor exceeds its supply growth, the wage level of unskilled labor increases, and the wage gap with skilled labor shrinks. Compared with manufacturing agglomeration, which mainly affects the supply and demand of unskilled labor, the agglomeration of producer services industry mainly affects the demand for skilled labor since it has higher threshold of labor force because of its high technical content. Moreover, due to the large differences in technical expertise among productive service industries, agglomeration development can produce greater knowledge and technology spillover effects, increase productivity, raise wages for skilled labor, and thus expand skill premiums. Inter-industrial agglomeration has a significant negative impact on the skill premium. For every 1\% increase in inter-industrial agglomeration, skill premium decreases by $0.36 \%$. Obviously, the impact of inter-industrial agglomeration on skill premium is smaller than that of manufacturing agglomeration and producer servers agglomeration. Different from the way in which the intra-industry agglomeration affects the skill premium, the inter-industry agglomeration can increase the supply of skilled labor. Because of the strong complementarity and correlation between manufacturing industry and producer service industry, the cooperative agglomeration development is beneficial to the knowledge and technology spillover effect ${ }^{[9]}$. The geographical proximity of firms is conducive to the exchange, dissemination and absorption of knowledge, and the transformation of unskilled labor in the manufacturing industry into skilled labor through 
"learning by doing" increases the supply of skilled labor, thus reducing the skill premium. Secondly, the manufacturing industry can work together with the productive service industry to accelerate industrial upgrading, enhance the value chain, improve labor productivity, thereby increasing the wage level of manufacturing, lower skill premium. Models (4) - (5) show that the agglomeration factors that cause the skill premium to expand at different times are different. The rise in skill premiums was relatively slow from 1989 to 2002, mainly due to the relatively high level of aggregation in the manufacturing sector that significantly reduced the skill premium level while the expansion of producer services agglomeration and inter-industrial agglomeration significantly increased skill premium level. So the rise is not obvious. From 2003 to 2014, skill premium rose rapidly. On the one hand, the sharp decline in the level of manufacturing agglomeration greatly weakened its ability to shrink the skill premium. On the other hand, the rapid increase in producer services agglomeration and the rapid decline in inter-industrial agglomeration significantly expanded the skill premium.

Table 1 Estimated results of skill premium model

\begin{tabular}{|c|c|c|c|c|c|}
\hline & Model (1) & Model (2) & Model (3) & Model (4) & Model (5) \\
\hline${\ln a g g^{m}}^{m}$ & $\begin{array}{c}-0.711^{* * *} \\
(-4.21)\end{array}$ & $\begin{array}{c}-0.580 * * * \\
(-2.87)\end{array}$ & $\begin{array}{c}-0.608 * * * \\
(-3.59)\end{array}$ & $\begin{array}{c}-2.337 * * * \\
(-6.23)\end{array}$ & $\begin{array}{l}-0.102 \\
(-0.45)\end{array}$ \\
\hline $\ln a g g^{s}$ & $\begin{array}{c}0.544^{* * * *} \\
(4.24)\end{array}$ & $\begin{array}{l}0.322 * \\
(2.01)\end{array}$ & $\begin{array}{c}0.391 * * \\
(2.31)\end{array}$ & $\begin{array}{c}1.553^{* * * *} \\
(5.12)\end{array}$ & $\begin{array}{c}0.562^{*} \\
(1.87)\end{array}$ \\
\hline $\ln a g g^{c o}$ & & $\begin{array}{c}-0.517 * * * \\
(-3.83)\end{array}$ & $\begin{array}{c}-0.360 * * \\
(-2.39)\end{array}$ & $\begin{array}{c}2.032^{* * *} \\
(4.15)\end{array}$ & $\begin{array}{c}-0.636 * * \\
(-2.66)\end{array}$ \\
\hline $\ln b t e$ & & & $\begin{array}{c}0.065 * * * \\
(4.79)\end{array}$ & $\begin{array}{l}0.028 * \\
(1.92)\end{array}$ & $\begin{array}{c}0.026 \\
(1.14)\end{array}$ \\
\hline $\ln l d b$ & $\begin{array}{c}0.282 * * * \\
(2.82)\end{array}$ & $\begin{array}{c}0.324 * * * \\
(3.22)\end{array}$ & $\begin{array}{c}0.376^{* * * *} \\
(4.08)\end{array}$ & $\begin{array}{c}0.169 * * \\
(2.2)\end{array}$ & $\begin{array}{c}0.681 * * * \\
(3.05)\end{array}$ \\
\hline $\ln z c b$ & $\begin{array}{c}-0.369 * * \\
(-2.09)\end{array}$ & $\begin{array}{c}-0.530 * * * \\
(-3.19)\end{array}$ & $\begin{array}{c}-0.718^{* * *} \\
(-4.67)\end{array}$ & $\begin{array}{c}-0.316 \\
(-0.77)\end{array}$ & $\begin{array}{c}-0.251 \\
(-1.24)\end{array}$ \\
\hline lnopen & $\begin{array}{l}0.053 \\
(0.7)\end{array}$ & $\begin{array}{c}0.024 \\
(0.35)\end{array}$ & $\begin{array}{c}0.070 \\
(1.09)\end{array}$ & $\begin{array}{c}-0.142^{* *} \\
(-2.52)\end{array}$ & $\begin{array}{c}0.330 * * * \\
(4.33)\end{array}$ \\
\hline $\ln c d$ & $\begin{array}{c}0.318 * * * \\
\quad(4.7)\end{array}$ & $\begin{array}{c}0.326 * * * \\
(4.87)\end{array}$ & $\begin{array}{c}0.364 * * * \\
(6.05)\end{array}$ & $\begin{array}{c}0.477 * * * \\
(5.56)\end{array}$ & $\begin{array}{c}0.223 * * \\
(2.16)\end{array}$ \\
\hline $\operatorname{lngov}$ & $\begin{array}{c}-0.350^{* * *} \\
(-2.92)\end{array}$ & $\begin{array}{c}-0.368 * * * \\
(-3.21)\end{array}$ & $\begin{array}{c}-0.352^{* * *} \\
(-3.5)\end{array}$ & $\begin{array}{c}-0.371^{* * *} \\
(-4.74)\end{array}$ & $\begin{array}{c}-0.273 \\
(-0.79)\end{array}$ \\
\hline _cons & $\begin{array}{c}4.098 * * \\
(2.23)\end{array}$ & $\begin{array}{c}5.716^{* * * *} \\
(3.38)\end{array}$ & $\begin{array}{c}7.970 * * * \\
(5.1)\end{array}$ & $\begin{array}{c}2.976 \\
(0.71)\end{array}$ & $\begin{array}{c}4.783 * * \\
(2.57)\end{array}$ \\
\hline $\mathrm{N}$ & 286 & 286 & 286 & 154 & 132 \\
\hline $\mathrm{R}^{2}$ & 0.456 & 0.471 & 0.493 & 0.643 & 0.255 \\
\hline $\mathrm{F}$ & 61.04 & 56.26 & 83.87 & 587.91 & 53.44 \\
\hline
\end{tabular}

Note: $*, * *, * * *$, represents the pass of significance test of $10 \%, 5 \%, 1 \%$, respectively. The values in parentheses are the t-test values.

The estimated coefficient of labor market entry barriers is statistically significant positive, indicating that the continuous improvement of the labor market has reduced the barriers to entry and narrowed the skill premium. However, compared to industrial agglomeration, labor market entry barriers have a much smaller impact on skills premiums, 1\% decline in labor market entry barriers can lead to $0.065 \%$ reduction in skill premiums. The results of the phased estimation show that, from 1989 to 2002, the labor market entry barriers have a significant positive impact on the skill premium. This is mainly due to the serious institutional obstacles still existed in China during this period. The monopoly industries and the state-owned economy make the labor force unable to realize the optimal allocation of resources through free flow, which leads to the continuous expansion of the skill premium to a certain extent. From 2003 to 2014, the impact of labor market entry barriers on skill premium is not significant at the $10 \%$ significance level. With the continuous 
improvement of China's labor market, industry and sector monopoly has been gradually broken, the degree of marketization of non-competitive labor market has been enhanced, thus barriers to entry of skilled labor has been reduced, and skills premium will gradually disappear.

\section{Conclusion and Policy Suggestion}

In this paper, a unified analysis framework is constructed to consider the effect of industrial agglomeration and labor market segmentation on the premium of skills, taking into account the characteristics of China's labor market segmentation. And empirical analysis is carried out based on the panel data from 1989 to 2014

The results show that industrial agglomeration has a significant effect on skill premium, but the effect of different industrial agglomeration is different. Manufacturing agglomeration, inter-industrial agglomeration have a significant negative impact on skill premium, and producer services agglomeration has a significant positive impact. The entry barrier caused by labor market segmentation has a significant positive impact on skill premium. The improvement of the labor market and the reduction of labor market entry barriers can effectively reduce the skill premium.

From the perspective of dynamic analysis, the skill premium increased relatively slowly from 1989 to 2002. It is mainly because that the negative influence of manufacturing agglomeration on skill premium to a large extent offsets the positive impact of producer services agglomeration and inter-industry agglomeration on skill premium. From 2003 to 2014, skill premiums rose rapidly. On the one hand, the negative impact of manufacturing agglomeration on skill premium is greatly weakened. On the other hand, due to the rapid increase of producer services agglomeration level and the rapid decline of inter-industrial agglomeration, the skill premium is expanded significantly.

Based on the results of empirical analysis, suggestions on reducing the skill premium are given as follows:

Firstly, speed up the development of industrial agglomeration and strengthen the construction of the labor market to reduce skill premium. Because of the space effect of industrial agglomeration and the optimization of the spatial structure of labor force, it is necessary to let labor flow reasonably and freely, which undoubtedly need to eliminate the multiple division of the labor market.

Secondly, improvement of labor market and reduction of labor market entry barriers can reduce the skill premium. On one hand, it is necessary to speed up the system construction, eliminate the labor division caused by household registration, industry and ownership and realize the free flow of labor force to make full use of the spatial effect of industrial agglomeration and reduce the skill premium; On the other hand, special attention should be paid to the division of the labor force resulting from the college entrance examination system. We should establish a multi - channel vocational skills training system, strengthen the cultivation of unskilled labor force, promote the transformation of unskilled labor to skilled labor force and increase the effective supply of skilled labor force.

\section{Acknowledgement}

This research was financially supported by the following projects: (1) General Project of Humanities and Social Sciences Research of the Ministry of Education. "Research on Innovation Performance and Innovation Path of Patent-Intensive Industries” (Granted No. 17YJC790003); (2) Soft Science Project of Guangdong Science and Technology Department in 2015.” Cultivating and 
Institutional Innovation of Guangdong's Strategic Emerging Industries' Core Competence” (Granted No. 2015A070704006); (3) Philosophy and social science project of Guangdong province in 2014.” Research on Cooperative Aggregation of Manufacturing and Producer Services in Guangdong (Granted No. GD14YLJ01); (4) Philosophy and social science project of Guangzhou in 2015.” Research on the Development Mechanism and Path for the Integration of Modern Service Industry and Manufacturing Industry in Guangzhou)(Granted No. 15G06).(5) 2015 Central University' Fundamental Research Funds (Social Science). "Study on the upgrades of productive services industry in the context of expanding employment" (project number: 2015QNXM21).

\section{References}

[1] Dong Zhiqing, Wang Fangling, Gao Qingkun. Is skill premium derived from the bias of technological progress?[J]. Statistical Research, 2013,(6):37-44.

[2] Shao Min, Liu J. Foreign capital entry and skill premiums - Also on the bias of China's FDI technology spillovers [J]. World Economic Research, 2011, (1): 67-74.

[3] Song Donglin, Wang Linhui, Dong Zhiqing. Does skill-biased technological progress exist?__Evidence from China [J]. Economic Research, 2010, (5): 68-81.

[4] Cao Jianyun. Labor mobility, regional concentration of human capital and promotion of human capital[J]. Journal of South China University of Technology, 2016,(9):36-42.

[5] Yang Renfa. Industrial Agglomeration and Regional Wage Gap: An Empirical Study Based on 269 Cities in China [J]. Management World, 2013, (8): 41-52.

[6] Wei L, Xu B. Globalization, State-Owned Enterprise Reform, and China's Wage Inequality[M]. Economic Globalization and China, Fudan University Press, 2003.

[7] Wang Dewen, Wu Yaowu, Cai Yi. Migration, Unemployment, and Urban Labor Market Segmentation [J]. World Economic Papers, 2004, (1): 37-52.

[8] Chen Guoliang, Chen Jianjun. Industrial Associations, Spatial Geography and Common Gathering of Secondary and Tertiary Industries: An Empirical Survey of 212 Cities in China [J]. Management World, 2012, (4): 82-100.

[9] Jacobs J. The Economy of Cities [M]. New York: Random House, 1969. 